\title{
O Estado de Coisas Inconvencional: trazendo a Corte Interamericana de Direitos Humanos para o debate sobre o sistema prisional brasileiro ${ }^{1}$
}

\section{Siddharta Legale Ferreira}

Professor de Direito Constitucional da Universidade Federal de Juiz de Fora (UFJF). Doutorando em Direito Internacional pela Universidade do Estado do Rio de Janeiro (UERJ). Mestre em Direito Constitucional e Bacharel pela Universidade Federal Fluminense (UFF). E-mail: siddhartalegale@yahoo.com.br

\section{David Pereira de Araújo}

Acadêmico da Universidade Federal de Juiz de Fora (UFJF). Monitor de Direito Constitucional. Extensionista do Projeto "Debates Virtuais". E-mail: david-araujo@hotmail.com

\section{Resumo}

O conceito de um Estado de Coisas Inconvencional não existe com esses termos na jurisprudência da Corte Interamericana de Direitos Humanos. Trata-se de uma proposta autoral que, relacionando a ideia da Corte Constitucional Colombiana sobre o "Estado de coisas inconstitucional" com os direitos humanos pretende permitir uma maior visibilidade às violações à Convenção Americana de Direitos Humanos, bem como à possibilidade de pensar um "controle de convencionalidade por omissão construtivo" de soluções para as violações de direitos à vida, integridade física, saúde etc., garantidos não só como direitos fundamentais pela Constituição de 1988, mas também como direitos humanos pela $\mathrm{CADH}$.

Palavras-chave

Estado de Coisas Inconvencional; Corte Interamericana de Direitos Humanos; Controle de Convencionalidade; Direitos Humanos.

\footnotetext{
${ }^{1}$ Agradecemos ao grupo de estudos "Estado de Coisas Inconstitucional e o Presídio de Governador Valadares", bem como à PROPESQ da Universidade Federal de Juiz de Fora (UFJF). 


\title{
The "Unconventional State of Affairs": Bringing the Interamerican Court of Human Right to debate on Brazilian Prisional System
}

\begin{abstract}
The concept of the "unconventional state of affairs" does not exist in these terms in the caselaw of the Interamerican Court of Human Rights. It is an authorial proposal, relating the idea of "unconstitutional state of affairs" from the Colombian Constitutional Court in order to allow greater visibility to the violations of the American Convention of Human Rights, as well as the chance to think a 'conventionality control for constructive omission" solutions for rights violations related to life, physical integrity, health, etc., not only guaranteed a fundamental rights in the Brazilian Constitution of 1988, but also as human rights by the ACHR.

Keywords

Unconventional State of Affairs; Interamerican Court of Human Rights; Conventionality Control; Human Rights.
\end{abstract}

\section{Sumário}

1. Aspectos gerais. 2. Estado de Coisas Inconstitucional. 3. Estado de Coisas Inconvencional. 4. Apontamentos finais. 5. Referências bibliográficas.

\section{Aspectos Gerais}

Na liminar da ADPF 347 do Supremo Tribunal Federal Brasileiro (STF)², o Ministro Marco Aurélio importou a teoria do Estado de Coisas Inconstitucional (ECI), oriunda da Corte Constitucional da Colômbia. O STF declarou a existência de um Estado de Coisas inconstitucional no sistema carcerário brasileiro. Do ponto de vista prático, dois pedidos da petição foram deferidos pela Corte: a impossibilidade de contingenciamento das verbas do fundo penitenciário pelo Executivo e a obrigatoriedade da apresentação imediata do preso ao juiz, relacionada às audiências de custódia. Do ponto de vista teórico, a medida evidencia os limites do controle judicial da omissão apenas com base em omissões legislativas ${ }^{3}$, apontando para a necessidade de pensar a inefetividade concreta dos direitos fundamentais também como uma omissão inconstitucional igualmente sindicável ${ }^{4}$.

\footnotetext{
${ }^{2}$ STF, ADPF 347 MC, Rel. Min. Marco Aurélio, J. 09.09.2015

${ }^{3}$ Sobre o modelo clássico de eficácia jurídica das normas, SILVA, José Afonso da. Aplicabilidade das normas constitucionais. São Paulo: Malheiros, 2001.

${ }^{4}$ Sobre a doutrina brasileira da efetividade, enfatizando a necessidade de pensar a eficácia social e não apenas jurídica das normas, cf. BARROSO, Luís Roberto. A efetividade das normas constitucionais: por que não uma Constituição para valer? In: $O$ novo direito constitucional brasileiro: contribuições para a construção teórica e prática da jurisdição constitucional no Brasil. Belo Horizonte: Editora Forum, 2012. E do mesmo autor, A doutrina brasileira da efetividade. In: Temas de direito constitucional, t. III. Rio de Janeiro: Renovar, 2005.
} 
O reconhecimento de um $\mathrm{ECl}$ pressupõe, dentro dos parâmetros fixados pela Corte Constitucional colombiana, especialmente nas tutelas T-25/2004 ${ }^{5}$ e T-153 ${ }^{6}$, que exista grave e massiva violação dos direitos fundamentais, uma omissão persistente do Estado em resolvê-la e, ainda, um litígio estrutural a demandar soluções interinstitucionais para os problemas. Uma instituição sozinha seria incapaz de resolver os dilemas vivenciados, dado o volume de casos envolvendo questões, como, por exemplo, prisionais e de deslocamento forçado de pessoas. Carlos Alexandre ${ }^{7}$ e Jane Reis ${ }^{8}$ vêm destacando a possibilidade de pensar inconstitucionalidades sistêmicas, multidimensionais, que as respostas do legislativo são insuficientes para resolver os dilemas da omissão inconstitucional, que acaba por ocasionar uma tutela deficiente dos direitos fundamentais. Pretendemos propor, a partir dessas bases, a criação do conceito de um "Estado de Coisas Inconvencional", investigando em que medida existe também uma violação massiva da Convenção Americana de Direitos Humanos (CADH), também conhecida como Pacto de São José da Costa Rica, decorrente da omissão do Estado Brasileiro, somada a uma proposta que integre à Comissão Interamericana de Direitos Humanos (CIDH) e a Corte Interamericana de Direitos Humanos (Corte IDH) nesse litígio estrutural.

As condenações do Brasil na Corte, notadamente nos casos dos Presídios de Urso Branco, Pedrinhas e de Curado, entre outros, fornecem lastro empírico suficiente para embasar o conceito paralelo ao de ECI. Os elementos substantivos dos casos da Corte IDH são suficientemente análogos às T-25 da CCC, T-153 da CCC e ADPF 347 do STF.

Repita-se, por fim, que o conceito de um Estado de Coisas Inconvencional não existe com esses termos na jurisprudência da Corte IDH. Trata-se de uma proposta autoral que, relacionando ideias da Corte Constitucional Colombiana sobre o "Estado de coisas inconstitucional", de modo a permitir uma maior visibilidade às violações à CADH, bem como à possibilidade pensar um "controle de convencionalidade por omissão construtivo" de soluções para as violações de direitos à vida, integridade física, saúde etc.,

${ }^{5}$ CCC, Sentencia T-025/04, Magistrado Ponente: Dr. Manuel José Cepeda Espinosa, J. 22.01.2004.

${ }^{6}$ CCC, Sentencia T-153/13, Magistrado Ponente: Alexei Julio Estrada, J. 20.03.2013.

${ }^{7}$ Veja-se a criativa critica à classificação tradicional das normas quanto à eficácia do Professor José Afonso da Silva, no capítulo 1 e 2 cf. CAMPOS, Carlos Alexandre de Azevedo. Da Inconstitucionalidade por omissão ao "Estado de Coisas Inconstitucional. Rio de Janeiro. Tese de Doutorado. Universidade do Estado do Rio de Janeiro. Rio de Janeiro. 2015.

${ }^{8}$ Para uma abordagem mais ampla do tema, percorrendo inclusive à jurisprudência do STF, cf. PEREIRA, Jane Reis Gonçalves; GONÇALVES, Gabriel Accioly. Inconstitucionalidade sistêmica e multidimensional: transformações no diagnóstico das violações à Constituição. Jurispoiesis (Rio de Janeiro), v. 18, p. 130-159, 2015. 
garantidos não só como direitos fundamentais pela Constituição de 1988, mas também como direitos humanos pela CADH.

\section{O Estado de Coisas Inconstitucional}

O Estado De Coisas inconstitucional (ECl) é uma teoria desenvolvida no âmbito da Corte Constitucional da Colômbia (CCC). Segundo Carlos Alexandre Campos Azevedo, o ECI declara uma violação massiva a direitos fundamentais, oriunda de uma omissão persistente, envolvendo um litígio estrutural, tendo sido declarado pela CCC originalmente na Sentença de Unificação (SU) n. 559/19979. Tal sentença dizia respeito a professores, que entraram com ações judiciais porque as autoridades locais recusaram seus direitos previdenciários. A partir de tal quadro, a CCC começou a investigar erros e falhas do Estado que ocasionavam as violações anteriormente mencionadas.

Os dois casos de maior repercussão aplicando a teoria, porém, envolveram o "deslocamento forçado" de pessoas em virtude da violência interna (T-25/2004) ${ }^{10}$ e o sistema carcerário $(\mathrm{T}-153)^{11}$. No primeiro caso, indivíduos aterrorizados por grupo como as Forças Armadas Revolucionárias da Colômbia (FARC), buscavam a sua proteção e de seus familiares, migrando para outros territórios dentro da própria Colômbia. O número de famílias nesta situação adquiriu um patamar muito elevado. Mais de 1000 famílias se encontravam nessa situação ${ }^{12}$.

Em relação aos presídios, a T-153/1998 reconheceu a superlotação existente nas penitenciárias do país. A sentença pontuou quadro de violação massiva aos direitos humanos dos detentos das Penitenciárias Nacionais de Bogotá e de Bellavista em Medellín. A Corte Constitucional Colombiana a partir de análises e estudos empíricos constatou que as violações massivas a direitos fundamentais. Na penitenciária de Bogotá, em ações posteriores, apontou-se, por exemplo, as péssimas condições de higiene que atentavam contra a dignidade da pessoa humana $(T-815 / 13)^{13}$. Na Penitenciária de

${ }^{9}$ CAMPOS, Carlos Alexandre de Azevedo. Da Inconstitucionalidade por omissão ao "Estado de Coisas Inconstitucional. Rio de Janeiro. Tese de Doutorado. Universidade do Estado do Rio de Janeiro. Rio de Janeiro. 2015. Do mesmo autor, cf. Estado de Coisas Inconstitucional. Disponível em: <http://jota.uol.com.br/jotamundo-estado-de-coisas-inconstitucional >. Acesso em: 28. abr. 2016.

10 CCC, Sentencia T-025/04, Magistrado Ponente: Dr. Manuel José Cepeda Espinoza, J. 22.01.2004.

${ }^{11}$ CCC, Sentencia T-153/13, Magistrado Ponente: Alexei Julio Estrada, J. 20.03.2013.

12 Não desejamos discorrer sobre a questão do deslocamento forçado. Para uma análise da T-25, cf. GARAVITO, César Rodriguez; FRANCO, Diana Rodriguez. Juicio a la exclusión: El impacto de los tribunales sobre los derechos sociales en el Sur Global. Buenos Aires: Siglo Veintiuno Editores, 2015.

${ }^{13}$ CCC, T- j. 12 de novembro de 2013.

Revista Publicum

Rio de Janeiro, v.2, n. 2, 2016, p. 67-82

http://www.e-publicacoes.uerj.br/index.php/publicum

DOI: 10.12957/publicum.2016.26042 
Bellavista, o quadro dramático de superlotação obrigava um dos presos a dormir no banheiro, o que o fez ter doenças dermatológicas (T-256/00) ${ }^{14}$.

O mesmo quadro se repetia em grande parte das penitenciárias do país. Na Penitenciária de Villa Hermosa em Cali, por exemplo, vivenciava-se revistas íntimas atentatórias à privacidade e à dignidade humana por agentes não identificados por crachás (T-1139677) ${ }^{15}$. Ainda na Penitenciária de Villa Hermosa, em Cali, apontava-se a violação aos direitos humanos das mulheres, decorrentes das omissões em relação, por exemplo, ao remanejamento do direito de visitas íntimas, quando essas coincidissem com seus ciclos menstruais mensais $(\mathrm{T}-848 / 05)^{16}$. Na Penitenciária de Jericó, em Antioquia, a superlotação também corroía direitos fundamentais variados $(T-861 / 2013){ }^{17}$. Em casos do Presídio de Cartagena, São Sebastião Ternera, chegaram a conter relatos de torturas e abusos pelas autoridades, bem como inspeções vaginais para que a visita fosse autorizada ao detento (T-690/04 $\left.{ }^{18}\right)$.

O problema penitenciário é volumoso em número de demandas e envolve questões complexas. A busca de soluções na Colômbia envolveu o engajamento do Ministério da Justiça, do Poder Judiciário, do Instituto Nacional Penitenciário e Carcerário (INPEC) e diversos órgãos. Embora se deva reconhecer os limites e possibilidades do ECI no caso dos presídios em razão do monitoramento insuficiente pela $\mathrm{CCC}^{19}$, esse ativismo tornou público o tema e abriu espaço para um diálogo interinstitucional permitindo a busca por soluções.

O Estado de Coisas Inconstitucional, como se pode observar, envolve violações massivas, omissões persistentes e o litígio estrutural. A omissão do Poder Executivo ocorre, por exemplo, quando este não realiza as reformas necessárias, enquanto a do Poder Judiciário, quando a fiscalização é feita de forma deficiente. O diálogo entre os órgãos e a atuação conjunta de autoridades é fundamental para, pelo menos, tentar reverter o quadro dramático.

14 Bogotá. Corte Constitucional Colombiana. 06 de março de 2000 . Disponível em:<http://www.corteconstitucional.gov.co/relatoria/2000/T-256-00.htm >. Acesso em: 26.Mai.16.

${ }^{15}$ CCC, Sentencia T-1069/05, Magistrado Ponente: Dr. Rodrigo Escobar Gil, J. 20.10.2005.

${ }^{16}$ CCC, Sentencia T-848/05, Magistrado Ponente: Dr. Manuel José Cepeda Espinoza, J. 16.08.2005.

17 Bogotá. Corte Constitucional Colombiana. 27 denovembro de 2013. Disponível em:<http://www.corteconstitucional.gov.co/relatoria/2013/T-861-13.htm >. Acesso em: 26.Mai.16. ${ }^{18} \mathrm{CCC}, \mathrm{T}-$, j. 22 de julho de 2004.

19 VIEIRA, José Ribas; BEZERRA, Rafael. O Estado de Coisas fora do lugar? Disponível em: < http://jota.uol.com.br/estado-de-coisas-fora-lugar> 


\section{O Estado de Coisas Inconvencional}

O conceito do "Estado de Coisas inconvencional" parte, portanto, de duas linhas de argumentação. Em primeiro lugar, realiza-se um paralelismo com o Estado de Coisas Inconstitucional desenvolvido anteriormente, transpondo por analogias a questão para o plano internacional: violação massiva aos direitos humanos, omissão persistente do Estado em cumprir a Convenção Americana de Direitos Humanos e um litígio estrutural entre das entidades do Estado no plano horizontal da separação dos poderes, e vertical dos entres da federação.

Em segundo lugar, observa-se a jurisprudência contenciosa da Corte IDH, envolvendo presídios e estabelecimentos carcerários em sentido amplo. Significa que incluímos também casos envolvendo internação de menores de idade nas unidades socioeducativas e de indivíduos em geral em casas de repouso por possuírem deficiência mental. Perceba-se que, em termos qualitativos, as violações envolveram direitos humanos variados, como vida, integridade física, integridade moral, saúde, etc. de grupos vulneráveis ou em situação de vulnerabilidade: os presos, as crianças e os deficientes mentais.

Foram selecionados casos sobre a temática envolvendo o Estado Brasileiro, de modo que essa amostra permita comparações pertinentes à investida conceitual realizada aqui, bem como que permita evidenciar a existência no Brasil também de um Estado de Coisas Inconvencional. O sistema carcerário brasileiro encontra-se em um evidente estado de coisas inconstitucional e Inconvencional. O professor Daniel Sarmento chega a comparar os presídios brasileiros com as masmorras medievais ${ }^{20}$, dada o profundo grau de violação à dignidade humana presente nesses estabelecimentos ${ }^{21-22}$.

Só quem pode levar os casos até a Corte Interamericana é a Comissão Interamericana de Direitos Humanos ou o Estado. As famílias, Organizações NãoGovernamentais ou próprios indivíduos que tiveram os seus direitos violados só podem fazê-lo depois de esgotar as instâncias internas ${ }^{23}$, após uma longa batalha nacional e

${ }^{20}$ SARMENTO, Daniel Constituição e Sociedade: As masmorras medievais e o Supremo. Disponível em: < http://jota.info/constituicao-e-sociedade-masmorras-medievais-e-o-supremo >

21 SARMENTO, Daniel Dignidade da Pessoa Humana na Ordem Constitucional Brasileira: conteúdo, trajetórias e metodologia. Rio de Janeiro: Tese de Titularidade de Direito Constitucional da UERJ, 2015.

22 BARCELLOS, Ana Paula de. Violência urbana, condições das prisões e dignidade humana. Revista de Direito Administrativo n. 254, 2010.

${ }^{23}$ A respeito, confira-se a Opinião consultiva 11de 1990, que prevê exceções em caso de medo generalizado e pobreza extrema. Sobre o tema, cf. CANÇADO TRINDADE, Antônio Augusto. A regra do esgotamento dos recursos internos revisitada: desenvolvimentos jurisprudenciais recentes no âmbito da proteção 
internacional por acesso à justiça, tanto formal às instituições judiciais, quanto material como efetivo respeito aos seus direitos ${ }^{24}$.

A primeira decisão de caráter contencioso da Corte IDH envolveu a Medida Provisória de 18 de junho de 2002, referente à rebelião e aos assassinatos ocorridos no Presídio de Urso Branco, localizado em Porto Velho, Rondônia. Já a decisão contenciosa mais recente da Corte IDH envolve rebeliões e mortes violentas de detentos do Presídio de Curado, localizado em Recife, Pernambuco, em 18 de novembro de 2015. Entre um e outro, há casos de graves e massivas violações de direitos humanos de presos (Urso Branco, Araraquara, Curado, Pedrinhas), de internados em clínicas de repouso para deficientes mentais (Ximenes Lopes) e de menores (FEBEM do Complexo do Tatuapé).

A Casa de Detenção José Mario Alves, conhecida como Cárcere Urso Branco, localizada em Porto Velho, Rondônia (2002-2011) foi objeto de medidas provisórias ou provisionais pela Corte IDH, em 2002, em favor dos internos. O episódio dramático inicial envolveu a transferência das "celas de seguro" - destinadas a crimes considerados imorais pelos demais internos - e das "celas livres" - com certa liberdade de movimento no centro penal. O remanejamento dos detentos de ambas as celas de seguro nas celas da população carcerária em geral por decisão judicial acabou por desencadear um "homicídio sistemático" de diversos internos da "cela de seguro". Em 2 de janeiro de 2002, o grupo de choque ingressou no cárcere e encontrou 45 corpos dos internos. Alguns foram decapitados e outros tiveram braços e pernas mutilados. O governo informou que haviam falecido um número inferior: 27 pessoas. As condições do presídio como um todo violavam direitos humanos. A Corte IDH chegou a determinar que o Estado retirasse as armas do poder dos internos e investigasse os fatos que motivaram a adoção das medidas provisórias. Nos anos seguintes, diversas medidas provisórias foram deferidas, apontando violações aos direitos humanos, especialmente à vida e à integridade, que permaneceram ou novas em razão da superlotação, a necessidade de separação dos detentos e de responsabilidade penal e administrativa dos envolvidos.

Em 22 de abril de 2004, a Corte IDH destacou que não recebeu informação sobre a criação de um mecanismo apropriado para coordenar e supervisionar o cumprimento das medidas provisórias de 29 de agosto 2002, bem como não recebeu informes com a lista atualizada das pessoas em Urso Branco em 18 de junho de 2002. Isso demonstra o

internacional dos direitos humanos. In: Liber Amicorum, Héctor Fix-Zamudio, vol. I. São José da Costa Rica: Corte Interamericana de Direitos Humanos, Unión Europea, 1998.

${ }^{24}$ CANÇADO TRINDADE, Antônio Augusto. The access of individuals to international justice. Oxford: Oxford University Press, 2011. PIOVESAN, Flávia. Direitos humanos e justiça internacional. São Paulo Saraiva, 2007.RAMOS, André de Carvalho. Direitos humanos em juízo. São Paulo: Max Limonad, 2001.

Revista Publicum

Rio de Janeiro, v.2, n. 2, 2016, p. 67-82

http://www.e-publicacoes.uerj.br/index.php/publicum

DOI: $10.12957 /$ publicum.2016.26042 
descumprimento do dever estatal de informar à Corte sobre as medidas provisórias, que envolvem danos irreparáveis às pessoas em situação de extrema gravidade e urgência. Por essa razão, a Corte IDH considerou imprescindível escutar em audiência pública a CIDH, aos peticionários e ao Estado sobre o cumprimento das medidas ordenadas.

Em interessante voto concorrente na MP de 7 de julho de 2004, Cançado Trindade consignou que as obrigações de proteção no caso são erga omnes sob a proteção da CADH. Destacou que a obrigação geral de garantir abarca a aplicação das medidas provisórias, transferidas historicamente do processo civil para o direito internacional público, revestindo-se de um caráter verdadeiramente tutelar, mais do que cautelar. Enfatiza que tal obrigação impõe o reconhecimento dos efeitos da CADH tanto em relação ao Estado, quanto em face de terceiros em razão do dever de proteção no estado na relação entre os particulares (a chamada drittwirkung ${ }^{25}$ ), no caso, entre um preso e outro, sem a qual as obrigações convencionais seriam letra morta.

No caso envolvendo o Complexo Penitenciário de Araraquara, "Penitenciária Sebastião Martins Silveira", localizada no Estado de São Paulo (2006-2008), a Corte IDH decidiu requerer ao Estado que adote as medidas para proteger a vida e integridade física de todas as pessoas privadas de liberdade e das pessoas que ingressem na Penitenciária Dr. Sebastião Martins Silveira. Determinou a adoção as medidas necessárias e os cuidados para impedir que atos de força indevida sejam empregados por seus agentes no processo de recuperação e controle da Penitenciária.

Na primeira medida provisória de 28 de julho de 2006, a CIDH e os representantes destacaram a superlotação nos Centros de Detenção Provisórias; onde cabiam 496 estavam 600 pessoas, e a penitenciária destinada a cerca de 750 possuía 1000 internos, chegando a conter 1600 . As rebeliões e motins a um só tempo evidenciaram e agravaram a situação. Em determinado momento, o pavilhão foi destruído, tendo as portas de acesso ao pavilhão sido soldadas, o que deixou os presos, sem roupas, colchões, no frio de 10 , sem remédios ou assistência médica. A Corte IDH considerou que essa superlotação e esse isolamento do mundo exterior "implica um estado de completa insegurança e à mercê de toda a violência que pode produzir-se como consequência das precárias condições de detenção e da falta de segurança." (\$12)

Depois de recuperar o controle, determinou que: (i) o Estado permita o acesso do corpo médico, forneça alimentos, vestimentas e produtos de higiene; (ii) a diminuição da superlotação, a garantia de condições dignas de detenção, separando as pessoas conforme os padrões internacionais, bem como possibilitar a visita dos familiares dos

${ }^{25}$ SARMENTO, Daniel. Direitos fundamentais e relações privadas. Rio de Janeiro: Lúmen luris, 2004. 
reclusos; (iii) notifique a Corte IDH com a lista atualizada de todos os internos, constando a sua identidade, ingresso, transferência, liberação e movimentação nos setores da penitenciária; (iv) identifique os responsáveis e imponha sanções. Quatro medidas provisórias foram deferidas até que o Estado conseguisse que a Penitenciário funcionasse dentro de sua capacidade.

No caso envolvendo o Complexo Penitenciário de Pedrinhas, localizada no Maranhão (2014), a Corte IDH deferiu uma medida provisória para proteger o direito à vida e à integridade física dos presos em razão das rebeliões por conta da excessiva superlotação. Houve enfrentamentos, decapitações, reféns, agressões e torturas contra os presos pelos funcionários, militarização do Presídio pela entrada da força de segurança pública nacional e falta de atenção médica e alimentos aos presos em geral e aos que foram baleados, tuberculosos, com AIDs ou lepra. Havia falta de alimentos, água potável e material de higiene.

No caso envolvendo o Complexo Penitenciário de Curado, denominado "Professor Anibal Bruno", localizado na cidade de Recife em Pernambuco (2014-2015), a Corte IDH determinou a obrigação de o Estado de assegurar o respeito aos direitos humanos das pessoas privadas de liberdade no referido presídio, tanto contra agentes públicos, quanto em relação à terceiros. Enfatizou as deficiências das condições de segurança e o controle interno do Complexo de Curado, considerando imprescindível que o Estado adote medidas de curto, médio e longo prazo, propondo a adoção das seguintes: (i) elaborar e implementar um plano de emergência a respeito da atenção médica, em particular aos reclusos portadores de doenças contagiosas e tomar medidas para evitar a propagação das enfermidades; (ii) elaborar e implementar um plano de urgência para diminuir a situação de superpopulação do cárcere de Curado; (iii) eliminar a presença de armas de qualquer tipo dentro do Complexo de Curado; (iv) eliminar a presença de armas de qualquer tipo dentro do Complexo de Curado; (v) eliminar a prática de revistas humilhantes que afetem a intimidade e dignidade dos visitantes. Requereu que o Estado adote de forma imediata as medidas que sejam necessárias para garantir a vida e a integridade física das pessoas privadas de liberdade, assim como de qualquer pessoa no estabelecimento, como agentes penitenciários, funcionários e visitantes.

No caso envolvendo a Unidade de Internação Socioeducativa (UNIS), destinada a crianças e adolescentes, localizada no Município de Cariacica, no Estado do Espírito Santo (2011-2015), a Corte IDH reconheceu, através de informativos de órgãos do próprio estado, como o MP do ES, CNJ e pela administração da própria UNIS, a falta de controle do Estado e as constantes violações de Direitos Humanos no estabelecimento. Constatou 
também que não só a vida e a integridade física dos internos estavam em risco, como também a dos funcionários e pessoas que ali estavam. No dia 5 de abril de 2011, a UNIS contava com 108 adolescentes, sendo que sua capacidade máxima seria para 62 internos. Vários deles apresentavam marcas de disparos de balas de borracha. No módulo "Despertar III", um interno apresentava um corte profundo na cabeça, segundo ele, ocasionado pelo golpe de um agente. No dia 9 de dezembro de 2011, o adolescente "R", no Módulo Despertar 2, cortou seus próprios braços para que fosse retirado da cela, após 11 dias trancado. No dia 14 de novembro de 2011 o adolescente "C.S.", do Módulo Despertar 3, amarrou um pano em volta do pescoço e tentou se matar. Considerou que estavam presentes os requisitos necessários ao deferimento de uma medida provisória e ordenou ao estado: que tome as medidas necessárias para proteger a vida das crianças e adolescentes internados na UNIS; que as medidas adotadas deverão ser acompanhadas pelos representantes e pelos beneficiários no sentido de reduzir a superlotação, prestar assistência médica e conter o uso excessivo da força pelos agentes estatais contra os menores. A Corte IDH deferiu uma série de medidas provisórias na tentativa de regularizar a situação.

No caso do Complexo do Tatuapé da Fundação de Bem-estar do Menor (FEBEM), depois convertida em Fundação Casa, localizado no Estado de São Paulo (2005-2008), a Corte IDH adotou medidas em relação à FEBEM que fora criada em 1976 para ressocializar menores infratores através de medidas socioeducativas, que já contava com 77 unidades com 6.800 crianças e adolescentes internados sob custódia do estado. Houve diversas violações aos direitos fundamentais, como a morte de Alessandro da Silva, supostamente por cair do telhado; Jonathan Felipe foi morto com dois tiros da cabeça; e Cleber Nogueira por não receber o tratamento contra AIDs. Houve um motim nas Unidades 12 e 23 da FEBEM, com reféns, feridos, fogo em colchões, protestos, fugas massivas e mortos. A Corte IDH, considerando a extrema gravidade, urgência e o risco de danos irreparáveis aos direitos humanos à vida e à integridade, deferiu a medida provisória para proteger tais direitos das crianças e pessoas no complexo. Diversas medidas provisórias foram deferidas até a desativação do Complexo do Tatuapé. Na MP de 17 de novembro de 2005, considerando os acontecimentos, a Corte IDH, reconheceu a extrema gravidade, urgência e a necessidade de evitar danos irreparáveis ao direito à vida e integridade física das crianças e dos adolescentes privados de liberdade no referido centro e que "estão em grave risco e vulnerabilidade". A Corte IDH deferiu a MP para que o Estado adote de forma imediata medidas para proteger tais direitos das crianças e pessoas no complexo.

Revista Publicum

Rio de Janeiro, v.2, n. 2, 2016, p. 67-82

http://www.e-publicacoes.uerj.br/index.php/publicum

DOI: 10.12957/publicum.2016.26042 
Além disso, convocou uma audiência pública para escutar os argumentos de fato e as circunstâncias que motivaram a adoção da presente resolução.

O caso Damião Ximenes Lopes, envolvendo a Clínica de Repouso Guararapes, localizada em Sobral no Ceará (2006-2010). Esse é o primeiro caso com sentença e não apenas medida provisória deferida pela Corte ${ }^{26}$. Damião foi internado na Casa de Repouso Guararapes, localizada no Município de Sobral no Ceará. Ele faleceu em 4 de outubro de 1999, depois de 3 dias de internação. Embora privado, o hospital possuía um convênio com o Sistema Único de Saúde - SUS. As agressões a Damião começaram possivelmente quando ele estava tomando banho e, querendo permanecer mais um pouco, foi retirado à força por enfermeiros, sob a alegação de que teria adotado uma postura violenta. As péssimas condições da clínica não se circunscreviam a Damião. A sentença da Corte IDH, no caso, reconheceu a violação ao direito à vida (art. 4 da $\mathrm{CADH}$ ) e à integridade física (art. 5 da $(A D H)$ de Damião Ximenes Lopes, assim como ao direito à integridade física e moral (art. 5 da $\mathrm{CADH}$ ) e ao direito a garantias judiciais e à proteção judicial (art. 8 e 25 da CADH) de seus familiares, como a sua Mãe Albertina, sua irmã Irene, seu irmão Cosme e o seu pai, Francisco. Além disso, reconheceu como ilícita toda forma de exercício do poder público que viole os direitos reconhecidos na Convenção por ação ou por omissão (art. 1.1 da $\mathrm{CADH}$ ). Reconheceu a responsabilidade internacional o Estado, bem como o dever de indenizar pelos danos materiais, imateriais e custas e gastos dos mesmos.

\section{Apontamentos Finais}

É mesmo possível forjar um conceito de que existe um Estado de Coisas Inconvencional a partir da jurisprudência contenciosa da Corte IDH em relação ao Brasil?

Sim. Os casos descritos acima em termos qualificativos já forneceriam elementos suficientes para fundamentar essa conclusão. Ainda assim, quantificamos o total de casos contenciosos envolvendo apenas o Brasil para reforçar essa tese. Constatamos que, até outubro de 2016, existiam 35 medidas provisórias (MP), 5 sentenças (S) e 8 supervisões de cumprimento de sentença (SC). Em linhas gerais, percebe-se um elevado número de medidas provisórias em quantidade inclusive bastante superior em relação a todas as

${ }^{26}$ Vale conferir a excelente dissertação de mestrado da advogada da justiça global que atuou no caso que conta com uma pesquisa empírica com a família, cf. BORGES, Nadine. Damião Ximenes - Primeira condenação do Brasil na Corte Interamericana de Direitos Humanos. Rio de Janeiro: Revan, 2009, p. 25-66. Para uma contextualização mais ampla do caso, envolvendo os movimentos de luta pela reforma do sistema psiquiátrico, Cf. AGUIAR, Marcus Pinto. Acesso à justiça nos sistemas internacionais de proteção de direitos humanos. Rio de Janeiro: Lumen Juris, 2014, p.115 e ss. 
demais espécies de decisão; um reduzido número de sentenças propriamente ditas; e mais supervisões de sentença do que sentenças.

Esses dados são bastante reveladores. Em primeiro lugar, comprova a existência não apenas de violações aos direitos humanos, mas de violações graves. Isso porque as medidas provisórias pressupõem para serem aceitas violações graves e o risco de danos irreparáveis e não apenas o esgotamento das instâncias internas para que a Corte IDH possa apreciar a questão

Em segundo lugar, esses dados revelam também a existência de uma omissão persistente, porque, de um lado, a Corte IDH precisa reiterar sistematicamente as suas decisões para que se amplie o cumprimento das mesmas. Isso ocorre tanto no âmbito das medidas provisórias, quanto no âmbito das supervisões de cumprimento de sentença. Em geral, o Estado brasileiro cumpre apenas parcialmente as suas obrigações. Costuma indenizar, mas é omisso em relação às demais formas de reparação que exigem outras medidas não necessariamente pecuniárias. O cumprimento parcial não deixa de ser um descumprimento, o que em casos graves é, com o perdão do pleonasmo, ainda mais grave. A propósito, vale destacar esse ponto da omissão, tendo em vista que a duração do procedimento varia de 3 a 9 anos apenas no desenrolar das fases escrita, oral e de cumprimento na Corte IDH. Se somarmos o arrastado processo no plano doméstico que não teve êxito, ou mesmo o tempo entre a $\mathrm{CIDH}$ e a Corte IDH, o lapso temporal aumentaria exponencialmente. Mesmo assim, ficando apenas com o tempo de tramitação na Corte IDH, casos, como o caso do Presídio de Urso Branco, durou por 9 anos entre a primeira e última medida provisória proferida (2002-2011). O caso da Febem do Tatuapé durou 4 anos (2006-2008). O caso do Presídio de Araraquara consumiu por 3 anos (20062008). O caso Ximenes Lopes gastou 5 anos (2006-2010). O caso da UNIS levou 5 anos (2011-2015). O Presídio de Curado tem movimentações entre 2014 e 2015, mas nada em 2016. O caso de Pedrinhas tem apenas uma decisão (2014) e mais nada até 2016. Nos dois últimos casos, porém, não há novos documentos na Corte IDH com informações até 2016 sobre a situação atual do Presídio, o que torna um pouco inviável uma análise da duração do procedimento na Corte IDH.

Essa demora é particularmente dramática, quando se presta atenção para o fato de o esgotamento dos recursos internos e o processamento da $\mathrm{CIDH}$ consumirem um tempo precioso para os que têm urgência e precisam da proteção de direitos humanos. A questão é particularmente sensível por envolver grupos bastante vulneráveis, como os presos (ex: Urso Branco, Pedrinhas, Curado), os menores de idade nas unidades 
socioeducativas (FEBEM e UNIS) e aqueles em casas de repouso por possuírem deficiência mental (Damião Ximenes Lopes).

Por fim, em terceiro e último lugar, vale consignar que a Corte IDH e a $\mathrm{CIDH}$ podem desempenhar um papel relevante nesse litígio estrutural, cobrando ações concretas por parte do Estado, provocando uma atuação da União que não pode alegar no plano internacional que a segurança pública envolve uma competência federativa do Estado-membro. Mais do que isso, a reiteração de medidas provisórias, somadas aos mecanismos de supervisão de cumprimento de sentença consubstanciam um importante fase pós-deliberativa ou pós-decisória de acompanhamento da decisão e, a despeito dos limites e insuficiências, de ativismo judicial transnacional pode estimular um diálogo interinstitucional no plano interno, por exemplo, quando a Corte IDH cobrou um plano de emergência, como o fez no caso envolvendo o Presídio de Curado. Esse diálogo, por meio de uma maior intervenção da Corte IDH, aumentará potencial e gradativamente a efetividade dos direitos humanos previstos na $\mathrm{CADH}$, auxiliando o Estado brasileiro a reverter o atual Estado de coisas não só inconstitucional, mas também inconvencional.

\section{Referências Bibliográficas}

AGUIAR, Marcus Pinto. Acesso à justiça nos sistemas internacionais de proteção de direitos humanos. Rio de Janeiro: Lumen Juris, 2014, p.115.

BORGES, Nadine. Damião Ximenes - Primeira condenação do Brasil na Corte Interamericana de Direitos Humanos. Rio de Janeiro: Revan, 2009.

CAMPOS, Carlos Alexandre de Azevedo. Da Inconstitucionalidade por omissão ao "Estado de Coisas Inconstitucional. Rio de Janeiro. Tese de Doutorado. Universidade do Estado do Rio de Janeiro. Rio de Janeiro. 2015.

- Estado de Coisas Inconstitucional. Disponível em: <http://jota.uol.com.br/jotamundo-estado-de-coisas-inconstitucional>. Acesso em: 28. abr. 2016.

BARCELLOS, Ana Paula de. A eficácia jurídica dos princípios constitucionais: o princípio da dignidade da pessoa humana. Rio de Janeiro: Renovar, 2002.

. Violência urbana, condições das prisões e dignidade humana. Revista de Direito Administrativo n. 254, 2010.

BARROSO, Luís Roberto. A dignidade da pessoa humana no direito constitucional contemporâneo: a construção de um conceito jurídico à luz da jurisprudência mundial. Belo Horizonte: Fórum, 2014. 
A efetividade das normas constitucionais: por que não uma Constituição para valer? In: O novo direito constitucional brasileiro: contribuições para a construção teórica e prática da jurisdição constitucional no Brasil. Belo Horizonte: Editora Forum, 2012.

. A doutrina brasileira da efetividade. In: Temas de direito constitucional, t. III. Rio de Janeiro: Renovar, 2005.

Aqui, lá e em todo lugar: a dignidade da pessoa humana no direito contemporâneo e no discurso transnacional. Revista dos Tribunais vol 919, 2012.

As dimensões da dignidade da pessoa humana: construindo uma compreensão jurídico constitucional necessária e possível Revista Brasileira de Direito Constitucional n. 09, 2007.

e TIBURCIO, Carmen. Constituição e tratados internacionais: alguns aspectos da relação entre direito internacional e direito interno. In: TIBURCIO, Carmen e BARROSO, Luís Roberto. Direito Constitucional internacional. Rio de Janeiro: Renovar, 2013.

Neoconstitucionalismo e a constitucionalização do Direito (O triunfo tardio do direito constitucional no Brasil). In: SOUZA NETO, Cláudio Pereira de; SARMENTO, Daniel (orgs.). A Constitucionalização do Direito. Fundamentos Teóricos e Aplicações Específicas. Rio de Janeiro: Lumen Juris, 2007.

BUERGENTHAL, Thomas. Recordando los inicios de la Corte Interamericana de Derechos Humanos. Disponível em :< http://www.corteidh.or.cr/tablas/R06729-1.pdf $>$.

. The Inter-American Court of Human Rights. The American Journal of International Law, Vol. 76, No. 2,, 1982, p. 231-245.

BURGORGUE-LARSEN, Laurence; TORRES, Amaya Úbeda. The Inter-american Court of Human Rights. New York: Oxford university Press, 2011.

BURGORGUE-LARSEN, Laurence. La Corte Interamericana de los Derechos Humanos como Tribunal constitucional. WPIDEIR $n$ o 22, 2014. Disponível em: <https://www.univparis1.fr/fileadmin/IREDIES/CV professeurs/Laurence BURGORGUE L ARSEN/LBL-Working Papers on European Law and Regional Integration.pdf $>$.

CANÇADO TRINDADE, Antônio Augusto. The access of individuals to international justice. Oxford: Oxford University Press, 2011.

. Tratado de direito internacional dos direitos humanos vol. III. Porto Alegre: Sergio Antonio Fabris Editor, 2003.

A regra do esgotamento dos recursos internos revisitada: desenvolvimentos jurisprudenciais recentes no âmbito da proteção internacional dos direitos humanos. In: Liber Amicorum, Héctor Fix-Zamudio, vol. I. São José da Costa Rica: Corte Interamericana de Direitos Humanos, Unión Europea, 1998.

O sistema interamericano de direito humanos no limiar do novo século: recomendações para o fortalecimento de seu mecanismo de proteção. In: GOMES, Luiz Flávio; PIOVESAN, Flávia. O sistema interamericano de proteção dos direitos humanos e o direito brasileiro. São Paulo: Editora Revista dos Tribunais, 2000. 
Las clausulas pétreas de la proteccion internacional del ser humano: el acceso directo de los indivíduos a la justicia a nível internacional y la intangibilidade de la jurisdicción obligatoria de los tribunales internacionales de derechos humanos [2001]. In: O Direito Internacional em um mundo em transformação. Rio de Janeiro: Renovar, 2005.

GARAVITO, César Rodriguez; FRANCO, Diana Rodriguez. Juicio a la exclusión: El impacto de los tribunales sobre los derechos sociales en el Sur Global. Buenos Aires: Siglo Veintiuno Editores, 2015.

OLIVEIRA, Thiago aleluia ferreira de. O controle de convencionalidade dos tratados de direitos humanos em perspectiva comparada: Brasil, Argentina e Chile. Rio de Janeiro: Dissertação de Mestrado UNESA-RJ, 2016.

PASQUALUCCI, Jo M. The practice and procedure of the Inter-American Court of Human Rights. New York: Cambridge University Press, 2013.

PIOVESAN, Flávia. Direitos humanos e justiça internacional. São Paulo Saraiva, 2007.

. Direitos humanos e o Direito constitucional internacional. São Paulo: Saraiva, 2007.

. e VIEIRA, Renato Stanziola. A força normativa dos princípios constitucionais fundamentais: a dignidade da pessoa humana. In: PIOVESAN, Flávia (Org.). Temas de direitos humanos. São Paulo: Saraiva, 2010.

. Brasil e o sistema interamericano de proteção dos direitos humanos. In: Temas de Direitos Humanos. São Paulo: Saraiva, 2010.

Código de Direito Internacional dos direitos humanos. São Paulo: DPL Editora, 2008.

PEREIRA, Jane Reis Gonçalves; GONÇALVES, Gabriel Accioly. Inconstitucionalidade sistêmica e multidimensional: transformações no diagnóstico das violações à Constituição. Jurispoiesis (Rio de Janeiro), v. 18, p. 130-159, 2015.

RAMOS, André de Carvalho. Direitos humanos em juízo. São Paulo: Max Limonad, 2001.

O diálogo de Cortes: O Supremo Tribunal Federal e a Corte Interamericana de direitos humanos. In: Alberto Amaral Junior e Liliana Lyra Jubilut (Orgs.). O STF e o direito internacional dos direitos humanos. São Paulo: Quartier Latin, 2009.

SARMENTO, Daniel Constituição e Globalização: a crise dos paradigmas do direito constitucional. In: Programa de Pós-Graduação da UERJ. (Org.). Anuário Direito $e$ Globalização - "A soberania". Rio de Janeiro: Renovar, 1999, v. 1, p. 53-70.

Direitos fundamentais e relações privadas. Rio de Janeiro: Lúmen luris, 2004.

. Dignidade da Pessoa Humana na Ordem Constitucional Brasileira: conteúdo, trajetórias e metodologia. Rio de Janeiro: Tese de Titularidade de Direito Constitucional da UERJ, 2015. 
2012.

e SOUZA NETO, Cláudio Pereira. Direito constitucional. Belo Horizonte: Forum,

Entrevista - Brasil precisa desenvolver advocacia de interesse público. Disponível em: <http://jota.info/entrevista-daniel-sarmento>

SOUZA NETO, Cláudio Pereira. Direito constitucional: teoria, história e métodos de trabalho. Belo Horizonte: Editora Forum, 2012.

Constituição e Sociedade: As masmorras medievais e o Supremo. Disponível em: <http://jota.info/constituicao-e-sociedade-masmorras-medievais-e-o-supremo>.

Intepretação constitucional cosmopolita. Disponível em: <http://iota.info/interpretacao-constitucional-cosmopolita>.

SILVA, José Afonso da. Aplicabilidade das normas constitucionais. São Paulo: Malheiros, 2001.

VIEIRA, José Ribas; BEZERRA, Rafael. O Estado de Coisas fora do lugar? Disponível em: < http://jota.uol.com.br/estado-de-coisas-fora-lugar>.

Recebido em 15/10/2016

Aceito em 18/11/2016 